\title{
What Do Health Libraries Tweet About? A Content Analysis
}

\author{
Christine $\mathrm{J}$ Neilson \\ University of Manitoba Health Libraries \\ University of Manitoba \\ christine.neilson@umanitoba.ca
}

\begin{abstract}
Many libraries have adopted Twitter to connect with their clients, but the library literature has only begun to explore how health libraries use Twitter in practice. When presented with new responsibility for tweeting on behalf of her library, the author was faced with the question "what do other health libraries tweet about?". This paper presents a content analysis of a sample of tweets from 10 health and medical libraries in Canada, the United States, and the United Kingdom. Five hundred twenty-four tweets were collected over 4 one-week periods in 2014 and analyzed using a grounded theory approach to identify themes and categories. The health libraries included in this study appear to use Twitter primarily as a current awareness tool, focusing on topics external to the library and its broader organization and including little original content. This differs from previous studies, which have found that libraries tend to use Twitter primarily for library promotion. While this snapshot of Twitter activity helps shed light on how health libraries use Twitter, further research is needed to understand the underlying factors that shape libraries' Twitter use.
\end{abstract}

\section{Keywords}

Twitter, health libraries, content analysis

\section{Introduction}

This article describes a small study that came directly from the author's practice as an Information Specialist at St. Michael's Hospital, a large teaching and research hospital in Toronto, Ontario. When presented with new responsibility for tweeting on behalf of her health library, the author was faced with the question "what do other health libraries tweet about?". The literature did not give a satisfactory account of the content of health library tweets-were health library tweets primarily promoting the library, or were health libraries tweeting differently? This study attempts to answer these questions through a content analysis of publicly available tweets posted by 10 health and medical libraries located in Canada, the United States (US), and the United Kingdom (UK). The original literature search was conducted in early 2014 and data were collected during the same year. Naturally, discussion about libraries' use of Twitter continued after the author 
initially consulted the literature and so the literature review below has incorporated some articles published during and after the time this project was underway. This study was deemed exempt from the Ethics Review Board approval process by the St. Michael's Hospital Research Ethics Office.

\section{Literature Review}

Twitter is a free social media service that allows an account holder to broadcast brief messages to individuals who subscribe to-or follow - the account, and in turn receive messages from other Twitter account holders. Messages may be public or private. A number of features are currently available to enhance tweets, including: using hashtags (\#) to make posts related to a particular topic easier to find; using the symbol @ to mention another tweeter; and embedding images and video (Twitter, n.d.-b). According to Twitter's website there are over 300 million active Twitter users-more than $75 \%$ of which are based outside of the US-sending 500 million Tweets per day in 33 languages (Twitter, n.d.-a).

Given the widespread popularity of the platform, Twitter is seen by some as a valuable way to communicate with library clients about library services and events, library resources, and helpful library tips (Cole, 2009; Cuddy, Graham, \& Morton-Owens, 2010; Fichter \& Wisniewski, 2015). It can also be used to gain insight into clients' views of the library, either through direct feedback or using Twitter as a faux focus group by searching for what Twitter users are saying about a library in a given geographic area (Crawford, 2011; Hagman, 2012). In addition to being used as a method of communication, some see embracing Twitter and other social media platforms as a means of conveying the image of a library that keeps up with technology trends and seeks to engage with clients (Cuddy et al., 2010).

Some have gone so far as to declare that Twitter has become so mainstream in today's society that a library Twitter presence is no longer optional (Fichter \& Wisniewski, 2015). Cuddy and colleagues (2010) have asserted that the investment in time and effort involved in a library Twitter account are minimal so libraries should use Twitter regardless of the degree to which it boosts the impact of library outreach. Others argue that, regardless of the type of organization that is tweeting, a great deal of effort is required to effectively use Twitter to engage customers/clients and promote a business, service, or product. Vaynerchuk (2013) describes Twitter as "the cocktail party of the Internet," where a relationship is forged between the tweeter and their followers. To successfully implement Twitter, that relationship must feel like one between individuals rather than between a customer and a company; the tone, format, content, and context of tweets all play a role in the success of the connection, and a deliberate, concentrated approach is required to achieve that success (Vaynerchuk, 2013).

Even though many libraries have been using Twitter, some authors suggest that many of them may not be using it to its full potential for two-way communication about clients' views about the library, to enhance the client experience, or to effectively present itself as a "social" entity (Del Bosque, Leif, \& Skarl, 2012; Gunton \& Davis, 2012; Mon \& Lee, 
2015). Those who subscribe to the Twitter-as-hard-work paradigm suggest that every library should seriously consider whether adopting Twitter is worth the effort; If library clientele do not use it or there is not enough content to post regularly, a library may wish to focus its efforts elsewhere (Hagman, 2012). Verishagen and Hank (2014) have pointed out that, while it may sometimes seem like every other library is tweeting, this is not the case. Their inventory of Twitter accounts for English-language academic libraries in Canada indicated that less than half of the main libraries in these schools had their own Twitter presence (Verishagen \& Hank, 2014). Moreover, some libraries have begun disinvesting in social media activities based on feedback from clients who indicate that they would not be likely to use social media to connect with the library (Wu et al., 2014).

When this project began, there was a great deal of research available about how Twitter is used in general, but less examining how libraries make use of the service. Williams and colleagues (2013) examined 575 scholarly articles about Twitter from across disciplines, published between 2007 and 2011, which they assigned to four categories: Message, where the study focused on message content; User, where the user profile, their followers, etc. were the focus; Technology, where technological aspects were considered; and Concept, which includes discussion pieces, review articles and "... review[s] of how Twitter could be used in a particular setting such as a library." They found that for the sample as a whole, while a single publication may have incorporated more than one aspect, Message was the most common focus of academic publications about Twitter (61\% of publications), followed by User (21\%), Technology (10\%), and Concept (8\%). However, when the library literature was considered on its own, the distribution was quite different, with Message at 21\%, User at 0\%, Technology at 7\%, and Concept at $64 \%$ (Williams, Terras, \& Warwick, 2013). This is consistent with anecdotal observation of library literature, which until recently has tended to focus on describing Twitter as a potential tool for libraries and giving advice regarding its possible uses, rather than on examining how libraries are using Twitter in practice (Barnes, 2014; Giustini \& Wright, 2009; Jaquette, 2015). In recent years, research examining how libraries are using Twitter-as opposed to focusing on Twitter as a concept-seems to be increasing.

In 2014, Forbes and Hamilton examined tweets from the Twitter accounts of 59 Canadian research libraries over the course of a year. They developed seven account profiles based on the tweets posted: The Salesperson tended to rely heavily on marketing and promotional messages; The Mothership's messages focused on the broader organization; The Team Player tended to promote other libraries and the broader organization; The Curator focused on external events and current awareness; The Social Butterfly featured lighthearted tweets and personal exchanges; The Jack of All Trades displayed a mixture of the above; and The Delinquent account had a low level of activity or had been deleted (Forbes \& Hamilton, 2014).

Research has indicated that both academic and public libraries have tended towards the Salesperson persona. In 2010, Aharony compared academic and public library tweets from 30 US libraries, and identified four categories of tweets: tweets about the 
library, tweets sharing information about things outside of the library, tweets about technology, and miscellaneous tweets. The largest category of tweet for both types of libraries was tweets about the library (public: 52\%, academic: $37 \%$ ), but academic libraries primarily focused on the collection and services, while public libraries also focused on promoting library events and making book recommendations (Aharony, 2010). Del Bosque and colleagues (2012) found similar results in their 2012 study of academic library Twitter use, with the primary focus of tweets relating to library resources and promoting library events. Likewise, Shiri and Rathi's (2013) content analysis of tweets from the Edmonton Public Library (EPL) indicated that the library used Twitter primarily to communicate library-related announcements such as hours of operation, to share information about "books, movies and other media", and to provide recommendations "designed to lead the reader to the EPL catalogue". More recently, Young and Rossman (2015) reported a shift in Montana State University Library's tweeting behaviour away from tweets consistent with the Salesperson persona towards tweets that are more consistent with the Curator.

The author was particularly interested in what health libraries were tweeting, but examination of the literature did not reveal much in terms of the content of health libraries' Tweets. Waddell et al. (2012) examined Twitter feeds belonging to eight special libraries serving Canadian health organizations and hospitals, focusing on metrics that might point to the effective use of Twitter to further organizational goals and impact. These metrics included the use of hashtags, including links, and the number of retweets included on the feed. These practices varied between the organizations examined: the use of hashtags ranged from a feed containing no hashtags at all in its tweets, to a feed that included hashtags in $64 \%$ of its posts; links to content were included in $39 \%$ to $82 \%$ of tweets; and the use of retweets from other feeds ranged from one percent to $60 \%$ of tweets (Waddell, Barnes, \& Khan-Kernahan, 2012).

\section{Methods}

A pool of potential feeds to include in this study was created by searching Google for health|medical library site:Twitter.com in the spring of 2014. While Google can estimate the total number of results for a query into the thousands or millions, only the first 48 pages of results are accessible. As such, the first 480 search results were individually considered for relevance to the study. Twitter feeds for individual health science/medical libraries that were written in English were included in the pool of feeds. Twitter feeds that appeared to belong to individuals, health library associations or interest groups, consumer health libraries, library systems, libraries that served all disciplines, and feeds that were not written in English were excluded. A total of 121 possible library feeds were included in the pool.

A sample of 10 accounts was chosen at random from the pool by identifying positions in the pool list that corresponded to numbers generated by a random number generator. These accounts belonged to three special libraries and seven academic libraries: 
Special Libraries

- Frank Curtis Library - Hellesdon Hospital, Norwich, England

- Public Health Library - Hamilton Public Health Services, Hamilton, ON

- Treadwell Library - Massachusetts General Hospital, Boston MA

\section{Academic Libraries}

- Grunigen Medical Library - University of California Irvine, Irvine CA

- Health Sciences Library @ the UCF College of Medicine - University of Central Florida College of Medicine, Orlando FL

- Lyman Maynard Stowe Library - University of Connecticut, Farmington, CT

- Maternal and Child Health Library - National Center for Education in Maternal and Child Health, Georgetown University, Washington, DC

- New York Medical College Health Sciences Library - New York Medical College, Valhalla, NY

- The Commonwealth Medical College Library - The Commonwealth Medical College, Scranton, PA

- Tompkins-McCaw Library for the Health Sciences - Virginia Commonwealth University, Richmond, VA

Four one-week time periods in 2014 were selected at random -February 10 to 16; April 21 to 27; June 23 to 29; and August 11 to 17-and all tweets posted on the sample feeds during these times were collected for analysis.

A content analysis was carried out using a grounded theory approach to identify the themes present in the tweets collected (Kuckartz, 2014a, 2014b). Each tweet was examined and assigned both thematic and factual categories (Kuckartz, 2014a). Thematic categories are subjective and were assigned iteratively. For example, subject categories were identified, assigned, grouped, and revised as analysis progressed and an overall subject structure emerged. Factual categories are less subjective. They included the type of library the tweet came from-academic vs. special-and whether the post was a tweet or a retweet, where a retweet is re-posting another account holder's tweet by selecting the "retweet" function. An inventory of specific elements included in the tweets-mentions (@), hashtags(\#), embedded images and video, and links to more information-was also conducted.

\section{Results}

A sample of 524 tweets was collected. Three tweets were excluded from analysis because of insufficient content (for example, tweeting a URL alone). 451 of the tweets came from academic libraries, and 70 came from special libraries. 


\section{Themes}

The tweets collected in the sample naturally fell into three broad themes: purpose, focus, and subject.

Theme 1, Purpose, relates to whether the purpose of the tweet appeared to be promotion ( $n=169)$, current awareness $(n=346)$, or miscellaneous purposes $(n=6)$. Tweets that appeared to advertise a product, service, or event were considered promotional in nature, while tweets that simply reported current events or happenings were included in the current awareness category (see the Appendix for examples of tweets that were assigned to each category). The primary purpose of the academic library tweets was current awareness. The purpose of the special library tweets was more evenly split between current awareness and promotion, with current awareness tweets only slightly outnumbering promotional tweets (see Table 1).

Theme 2, Focus, refers to whether the information presented related to the tweeting library ( $n=90)$, the library's broader organization $(n=62)$, or to topics external to the library and its broader organization $(n=369)$. The majority of tweets fell into the External category for both types of library (see Table 2). The number of tweets from the special libraries that related to the library and the library's broader organization were more evenly distributed than for the academic health libraries (see Table 2). As Table 3 illustrates, the three most commonly cited sources of information for externally focused tweets, identified either through a retweet or an explicitly credited source, were the popular press and journals ( $n=264)$, government organizations $(n=17)$, and healthrelated programs/collaborations $(n=14)$.

\section{Table 1.}

Distribution of tweet purpose by library type

\begin{tabular}{|l|c|c|l|c|c|}
\hline \multicolumn{2}{|c|}{ Special Libraries (n=70) } & \multicolumn{3}{c|}{ Academic Libraries (n=451) } \\
\hline & count & $\%$ & & count & $\%$ \\
\hline Current awareness & 37 & $53 \%$ & Current awareness & 308 & $68 \%$ \\
\hline Promotion & 33 & $47 \%$ & Promotion & 137 & $30 \%$ \\
\hline Miscellaneous & 0 & $0 \%$ & Miscellaneous & 6 & $1 \%$ \\
\hline
\end{tabular}




\section{Table 2.}

Distribution of tweet focus by library type

\begin{tabular}{|l|c|c|l|c|c|}
\hline \multicolumn{3}{|c|}{ Special Libraries (n=70) } & \multicolumn{3}{c|}{ Academic Libraries (n=451) } \\
\hline & count & $\%$ & & count & $\%$ \\
\hline Library & 9 & $13 \%$ & Library & 81 & $18 \%$ \\
\hline Organization & 13 & $19 \%$ & Organization & 49 & $11 \%$ \\
\hline External & 48 & $69 \%$ & External & 321 & $71 \%$ \\
\hline
\end{tabular}

\section{Table 3.}

Sources credited within externally focused tweets

\begin{tabular}{|c|c|c|}
\hline Sources Credited & Special Libraries & Academic Libraries \\
\hline $\begin{array}{c}\text { Popular Press / } \\
\text { Journals }\end{array}$ & 6 & 258 \\
\hline $\begin{array}{c}\text { Professional } \\
\text { Organizations }\end{array}$ & 7 & 9 \\
\hline $\begin{array}{c}\text { Government } \\
\text { Organizations }\end{array}$ & 10 & 17 \\
\hline Individuals & 6 & 10 \\
\hline $\begin{array}{c}\text { Postsecondary } \\
\text { Institutions }\end{array}$ & 1 & 9 \\
\hline $\begin{array}{c}\text { Health Programs / } \\
\text { Collaborations }\end{array}$ & 14 & 14 \\
\hline Company / Vendor & 0 & 3 \\
\hline General Blog & 4 & 8 \\
\hline Miscellaneous & 0 & 2 \\
\hline None & 0 & 33 \\
\hline
\end{tabular}




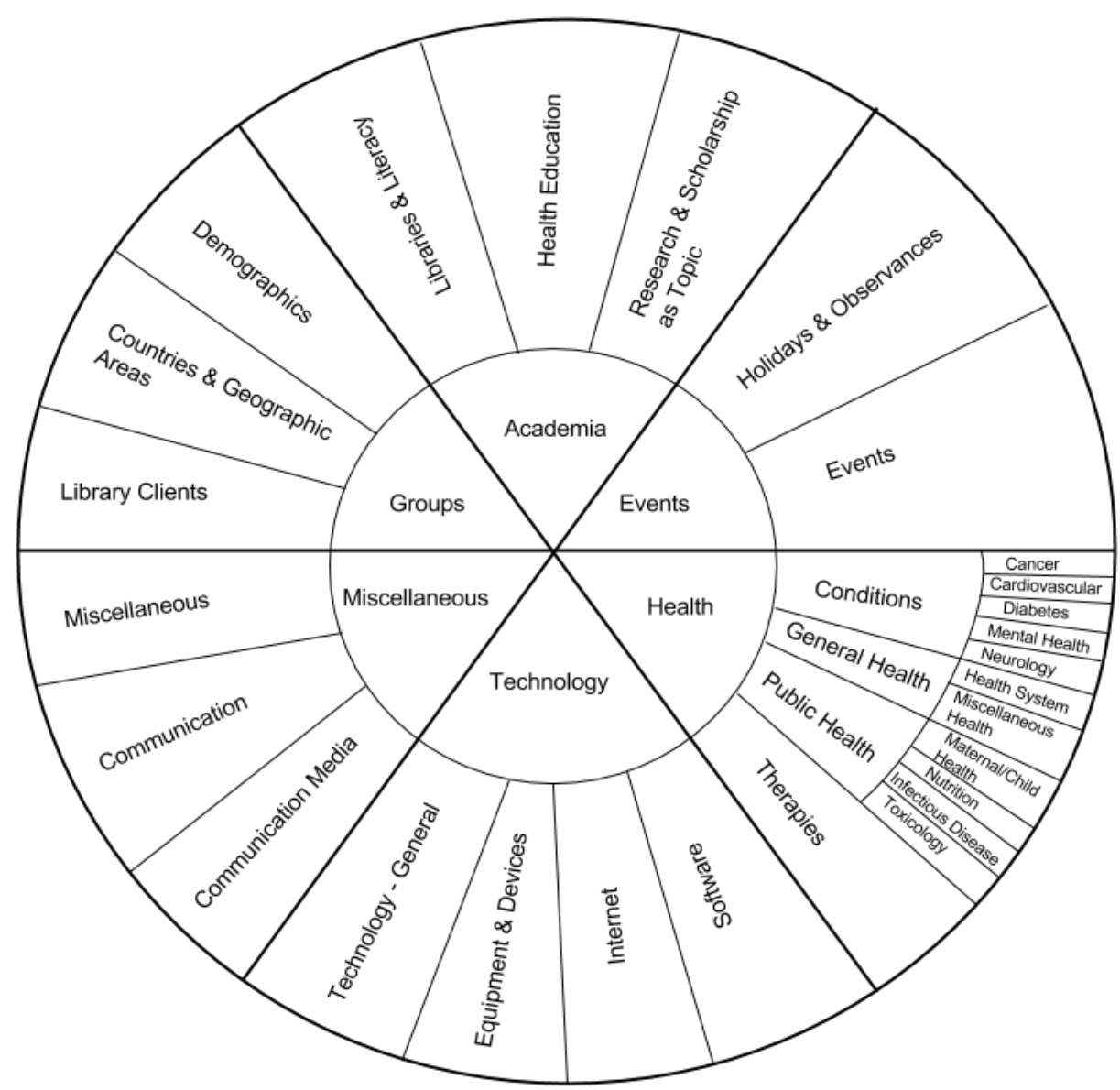

Figure 1. Subject categorization

Theme 3, Subject, refers to the topic or topics of the tweets. At the most granular level, the subjects of individual tweets varied widely and covered topics ranging from the 2014 Ebola outbreak to food trucks (see the Appendix for example tweets). Subject level categories were created based on the tweets collected (see Figure 1). At the broadest level, the topics of the tweets collected fell into one of the following categories:

Academia, Events, Health, Groups, Technology, or Miscellaneous. Within each of these categories, second-level subgroupings encompass more specific areas. In the case of the overall topic "Health", three of the second-level subgroups contained an additional layer of subtopics. Individual tweets could fall into several categories at the same time, such as the following:

\section{UCl Medical Library @Grunigen.Feb 13}

BCC Health: Belgium approves child euthanasia: Belgium becomes the first country in the world to allow child e... http://bbc.in/1gzHWTZ

This tweet simultaneously falls into two first-level subject categories, three second-level categories, and two third-level categories, as shown in Table 4 below: 
Table 4.

Example of multiple subject categorization of a tweet

\begin{tabular}{|c|c|c|c|}
\hline Topic & $\begin{array}{c}\text { First-Level } \\
\text { Category }\end{array}$ & Second-Level Category & $\begin{array}{c}\text { Third-Level } \\
\text { Category }\end{array}$ \\
\hline Legislation & Health & General Health & Health System \\
\hline Euthanasia & Health & General Health & $\begin{array}{c}\text { Miscellaneous } \\
\text { Health }\end{array}$ \\
\hline Children & Groups & Demographics & - \\
\hline Belgium & Groups & $\begin{array}{c}\text { Countries \& Geographic } \\
\text { areas }\end{array}$ & - \\
\hline
\end{tabular}

\section{Tweet vs. Retweet}

The tweets examined were a combination of original tweets and retweets from other Twitter accounts (see Table 5). Many original tweets related to information about the library and, in the case of the academic libraries, the broader organization. Externally focused tweets by the special libraries were exclusively retweets. The academic libraries used retweets much less frequently. However for most of the academic library current awareness tweets, the tweeter posted a headline or blurb highlighting the news item and provided a link to further information, but did not offer original commentary on the topic.

\section{Table 5.}

Tweet vs. retweet (tweet(retweet)), by library type, focus, and purpose

\begin{tabular}{|c|c|c|c|c|}
\hline & Tweet Focus & $\begin{array}{c}\text { Current } \\
\text { Awareness }\end{array}$ & Promotion & Miscellaneous \\
\hline \multirow{4}{*}{$\begin{array}{c}\text { Special } \\
\text { Libraries }\end{array}$} & Library & $0(0)$ & $7(2)$ & $0(0)$ \\
\hline & $\begin{array}{c}\text { Broader } \\
\text { Organization }\end{array}$ & $0(2)$ & $1(10)$ & $0(0)$ \\
\hline & External & $0(36)$ & $0(12)$ & $0(0)$ \\
\hline & Total & $0(38)$ & $8(24)$ & $0(0)$ \\
\hline \multirow{4}{*}{$\begin{array}{l}\text { Academic } \\
\text { Libraries }\end{array}$} & Library & $0(0)$ & $78(1)$ & $2(0)$ \\
\hline & $\begin{array}{r}\text { Broader } \\
\text { Organization }\end{array}$ & 1(3) & $38(4)$ & $2(1)$ \\
\hline & External & $263(41)$ & $11(5)$ & $1(0)$ \\
\hline & Total & $264(44)$ & $127(10)$ & $5(1)$ \\
\hline
\end{tabular}




\begin{tabular}{|c|c|c|c|c|c|c|}
\hline \multicolumn{7}{|c|}{ Number of tweets featuring one or more functional elements (tweet(retweet)) } \\
\hline & $\begin{array}{l}\text { Tweet } \\
\text { Focus }\end{array}$ & $\begin{array}{c}\text { mentions } \\
(@)\end{array}$ & $\begin{array}{c}\text { hashtags } \\
(\#)\end{array}$ & photos & videos & Links \\
\hline \multirow{4}{*}{$\begin{array}{l}\text { Special } \\
\text { Library }\end{array}$} & Library & 2(1) & $2(0)$ & $2(0)$ & $0(0)$ & 4(1) \\
\hline & $\begin{array}{r}\text { Broader } \\
\text { Organization }\end{array}$ & 1(5) & $0(4)$ & 1(3) & $0(0)$ & $0(7)$ \\
\hline & External & $0(21)$ & $0(21)$ & $0(5)$ & $0(2)$ & $0(44)$ \\
\hline & Total & 30 & 27 & 11 & 2 & 56 \\
\hline \multirow{4}{*}{$\begin{array}{c}\text { Academic } \\
\text { Library }\end{array}$} & Library & $8(1)$ & $13(0)$ & $8(0)$ & $0(0)$ & $61(0)$ \\
\hline & $\begin{array}{r}\text { Broader } \\
\text { Organization }\end{array}$ & 1(4) & $0(5)$ & $0(2)$ & $0(0)$ & $40(7)$ \\
\hline & External & $6(17)$ & $3(11)$ & $0(10)$ & $2(3)$ & $274(42)$ \\
\hline & Total & 37 & 32 & 20 & 5 & 424 \\
\hline
\end{tabular}

\section{Tweet Elements}

All of the functional elements considered in the study were used to varying degrees by both types of library (see Table 6). A link to more information was the most common element used in the sample. The use of hashtags(\#) and mentions(@) was much less common but present in tweets from both library types. Embedding photos was less common still, and the least used element was video. In the case of special library tweets, the only two videos included in the tweets examined were found in retweets.

\section{Discussion}

The sample of tweets examined in this study came primarily from academic libraries $(n=451)$, with a small number of tweets from special libraries $(n=70)$. This difference in the number of tweets can be explained by both the relatively large number of academic libraries included in the sample $(n=7)$ and the frequency of tweets in each library during the weeks that the sample was collected-the special libraries simply tweeted less often than the academic libraries during those times.

Based on the sample collected, it appears that these special and academic health libraries were using Twitter in a similar fashion. Unlike library Twitter feeds examined in previous studies, these libraries tended towards Forbes and Hamilton's Curator profile, using Twitter primarily as a current awareness tool, with a smaller degree of The 
Salesperson present. Most current awareness tweets were externally focused, but this was not always the case, such as this tweet from the Grunigen Medical Library (University of California at Irvine) about a measles warning at another University of California campus:

\section{uCl Medical Library @Grunigen.Feb 14}

CNN Health: Measles warning issued: Officials say a University of California, Berkeley student may have expose... http://bit.ly/1b2sAt8

Likewise, most promotional tweets were focused on the tweeting library but some were focused externally, such as this tweet from The Commonwealth Medical College Library that promoted a public library giveaway:

TCMC Medical Library @tcmclibrary · Jun 23

NICE!! Go get an awesome bag from the Scranton Public Library when you check out 5 items or more!! http://fb. me/31ae/wOOD

The subjects of the tweets were consistent both with the libraries' focus on external information and with their audience, featuring information related to various aspects of health, academia, and technology. Given that the majority of tweets sampled related to current events as opposed to information about the library or the library's broader organization, it is not surprising that the popular press was a major source of tweet content in the sample as a whole. However, it is interesting to note that the sources credited appear to be relatively more diverse in the special library tweets compared to those from the academic libraries, which relied more heavily on the popular press. One can only speculate as to why this difference in sources might occur. It may be a function of academic libraries tweeting for a broad audience within the health sciences and special libraries tweeting to clients with more focused areas of interest. It could be the result of an attempt by academic libraries to maintain a high frequency of tweets, where news makes for an easy source of regular fresh content. Or other, unknown factors could have influenced tweet content. The relatively high use of links to additional information is logical, both because of the limited amount of space available to deliver a message and because of the high proportion of externally focused tweets. The low use of more eye-catching tweets that embed photos or video, along with the small proportion of original content, could suggest that these libraries are approaching twitter as a low-effort supplement to existing current awareness and outreach efforts, as promoted by Cuddy and colleagues (2010). While the data presented here cannot tell us for certain if this is the case, a low effort approach to Twitter would be appealing in a busy library environment, particularly in smaller libraries with relatively few staff. In addition to the subject focus of the tweet content examined, the number of tweets vs. retweets is worth mentioning. Verishagen \& Hank have suggested that the number of tweets vs. retweets can act as an indication of how interactive a tweeter is. That is, more retweets could indicate more interactivity on the part of a tweeter (Verishagen \& Hank, 2014). The difference between the number of tweets and retweets between the 
two types of library in this sample is striking at first glance, however in this sample the difference is somewhat artificial; for many current awareness tweets the tweeter posted a catchy blurb about the news item and provided a link to further information, but did not offer original commentary on the topic. In this context, one could argue that there is essentially no difference between a tweet and a retweet about a news item.

So are the libraries included in the sample attempting to build a relationship with their clients by establishing a personal connection with followers as recommended by Vaynerchuk (2013)? Or is Twitter's utility viewed differently in these libraries? If these libraries assume that the relationship between the library and its clients is already established, perhaps Twitter's function is considered akin to email or RSS feeds: simply another mechanism of delivery. Crawford has pointed out that listening-or "lurking"over social media is an integral, but often overlooked and discounted, aspect of social media participation (Crawford, 2011). While some might criticize using Twitter for oneway communication, it is possible that some clients might find it acceptable or even desirable to receive information through Twitter without engaging in a conversation. Given there are many different tweeter archetypes, as described by Forbes and Hamilton (2014), one might argue that there is no single correct way to use Twitter so long as the goals of the tweeting library are being met.

The library tweets examined by the author focused less on library promotion than was previously found by Aharony (2010), Del Bosque and colleagues (2012), and Shiri and Rathi (2013). This could reflect a change over time in how libraries are using Twitter as the platform and our relationship with it evolve. Evidence that the way some libraries interact on Twitter might be changing can be found in Young and Rossmann's (2015) report on a shift in tweeting activity by the Montana State University Library (MSUL). Originally, MSUL tweets were heavily oriented towards the Salesperson persona, focused on advertising library workshops, events and resources, but after a conscious change in philosophy, tweeters focused on posts framed around "student life" and "local community"-essentially, tweeting about things their target audience would find interesting and showing some personality in the process, as advocated by Vaynerchuk. As a result of this change, MSUL saw an increase in the numbers of student followers and a dramatic increase in the level of interaction with their followers (Young \& Rossmann, 2015)

\section{Lessons and Limitations}

The information gathered from the sample tweets helped inform the author's own tweeting practice. Prior to conducting this study, the author felt at a loss when it was her turn to tweet for her library. After examining the way other health libraries were tweeting, she felt more confident when making choices about what content to tweet. The author personally found that sample tweets containing mentions and images were more interesting than the others. As a result, she began to use these elements more often in her own tweets. 
The information presented in this study is a useful addition to what is currently known about health libraries' Twitter use, however, the reader should be cognizant of three main limitations of this study.

The first limitation relates to the sampling method used. A relatively small number of Twitter feeds were selected for analysis in order to keep this project to a manageable size, and randomization was used in an attempt to minimize selection bias. In retrospect, the pool of potential accounts itself was largely influenced by the Google search engine in two ways. While the estimated number of results of the Google search was 90800 , Google limited the number of results it presented to the first 48 pages (i.e. the first 480 results). In addition, Google's personalization algorithms tailor search results based on a variety of factors including the searcher's geographic location and previous search history. This results in what is sometimes referred to as the "Google filter bubble" (Bonato, 2014). The pool of potential feeds for inclusion was influenced by the algorithm, and this likely accounts for the majority of accounts included in data analysis belonging to libraries that were located in the Eastern United States, despite random selection of individual Twitter feeds from the pool of potential feeds. The author was not familiar with the Google filter bubble phenomenon when the sampling method was devised, otherwise an alternative method of identifying potential twitter accounts would have been chosen. In addition, no distinction was made between academic and special libraries when devising the sampling method, but during data analysis comparing the differences and similarities between the two emerged as an interesting variable. Using a stratified random sample may have provided a more balanced picture.

Secondly, as is the case with other studies of this type, this study provides a snapshot of tweets for a specific set of libraries during a specific time. Twitter activity observed at these libraries may or may not translate to libraries in other geographic areas, and the activity observed during the sample periods may or may not be consistent with Twitter activity at these libraries at another time. This does not invalidate the study, but readers must be prepared to take this into account when drawing their own conclusions.

Third, and most importantly, the data presented here can tell us the "what" but it cannot tell us the "why"- we can only speculate. This content analysis does not address the underlying factors behind the tweets such as the purpose of the account, the characteristics of the individuals tweeting for the libraries, the Twitter habits of library clientele, or individual library policies and guidelines related to tweeting. This could be an interesting and informative area of future investigation.

\section{Conclusion}

The tweets examined here suggest that the academic and special health libraries included in this study have taken on the role of the Curator as described by Forbes and Hamilton, by focusing on tweeting current events and information related to the external environment. This project was initiated to answer a question - what do health libraries tweet about?-and it successfully provided a snapshot of Twitter activity for particular libraries at particular points in time, that author used to inform her practice. Social media 
and how we use it, both within libraries and in general, are continually evolving. Further research is needed to understand the underlying factors that shape Twitter use in libraries generally and in health libraries specifically.

\section{Acknowledgements}

My thoughts about Twitter have been influenced throughout the course of this project by various conversations with colleagues and the tweeting behaviors observed in this study. Thank you to the library staff at St. Michael's Hospital, Sarah Forbes (University of Toronto - Scarborough), and Virginia Wilson (University of Saskatchewan University Library, Centre for Evidence Based Library and Information Practice) for engaging in conversation about Twitter. I also owe thanks to the 10 libraries featured here for their example, and to the individuals who provided feedback on various stages of my manuscript.

Conflict of interest: None.

Source of Funding: None.

\section{References}

Aharony, N. (2010). Twitter use in libraries: An exploratory analysis. Journal of Web Librarianship, 4(4), 333-350.

Barnes, I. (2014). Twitter in special libraries: A distributed social media strategy. Public Services Quarterly, 10(1), 62-65.

Bonato, S. (2014). Googling the grey literature: Resources to augment your health research[ Webinar]. Medical Library Association (MLA) Webinar series.

Cole, S. (2009). 20 ways for librarians to use Twitter. Library Journal, 134(11), 25.

Crawford, K. (2011). Listening, not lurking: The neglected form of participation. In H. Grief, L. Hjorth, \& A. Lasén (Eds.), Cultures of participation (pp. 63-77). Berlin: Peter Lang.

Cuddy, C., Graham, J., \& Morton-Owens, E. G. (2010). Implementing Twitter in a health sciences library. Medical Reference Services Quarterly, 29(4), 320-330.

Del Bosque, D., Leif, S. A., \& Skarl, S. (2012). Libraries atwitter: trends in academic library tweeting. Reference Services Review, 40(2), 199-213.

Fichter, D., \& Wisniewski, J. (2015). The Twitter tipping point. Online Searcher, Sept / Oct 39(5), 74-76. 
Forbes, S., \& Hamilton, A. (2014). Twitter tactics: Analysing Canadian esearch Libraries' (CARL) use of Twitter. University of Toronto Scarborough.

Giustini, D., \& Wright, M.-D. (2009). Twitter: an introduction to microblogging for health librarians. Journal of the Canadian Health Libraries Association, 30(1), 11-17.

Gunton, L., \& Davis, K. (2012). Beyond broadcasting: Customer service, community and information experience in the Twittersphere. Reference Services Review, 40(2), 224-227.

Hagman, J. (2012). Joining the Twitter conversation. Public Services Quarterly, 8(1), 78-85.

Jaquette, E. Q. (2015). Social media posting tips for law library accounts. AALL Spectrum, 19(4), 16.

Kuckartz, U. (2014a). Basic concepts and the process of qualitative text analysis. In Qualitative text analysis: A guide to methods, practice \& using software (pp. 3765). London: SAGE Publications Ltd.

Kuckartz, U. (2014b). The building blocks of systematic qualitative text analysis. In Qualitative text analysis: A guide to methods, practice \& using software (pp. 1537). London: SAGE Publications Ltd.

Mon, L., \& Lee, J. (2015). Influence, reciprocity, participation, and visibility: Assessing the social library on Twitter/Influence, réciprocité, participation, et visibilité : Évaluation de la bibliothèque sociale sur Twitter. Canadian Journal of Information and Library Science, 39(3), 279-294.

Shiri, A., \& Rathi, D. (2013). Twitter content categorisation: A public library perspective. Journal of Information \& Knowledge Management, 12(04), 1-8.

Twitter. (n.d.-a). About.

Twitter. (n.d.-b). Twitter Help Center.

Vaynerchuk, G. (2013). Jab, jab, jab, right hook: How to tell your story in a noisy social world. New York: HarperCollins Publishers.

Verishagen, N., \& Hank, C. (2014). Are there birds in the library? The extent of Twitter adoption and use by Canadian academic libraries. First Monday, 19(11).

Waddell, D. C., Barnes, M., \& Khan-Kernahan, S. (2012). Tapping into the power of Twitter: A look at its potential in Canadian health libraries. Partnership: The Canadian Journal of Library \& Information Practice \& Research, 7(2), 1-12. 
Williams, S. A., Terras, M. M., \& Warwick, C. (2013). What do people study when they study Twitter? Classifying Twitter related academic papers. Journal of Documentation, 69(3), 384-410.

Wu J, Chatfield A.J., Hughes A.M., Kysh L, \& Rosenbloom M.C. A. (2014). Measuring patrons' technology habits: an evidence-based approach to tailoring library services. JMLA, 102(2), 125-129.

Young, S. W. H., \& Rossmann, D. (2015). Building library community through social media. Information Technology and Libraries, 34(1), 20-37. 


\section{Appendix: Examples of Tweets Collected} Special Libraries

\begin{tabular}{|c|c|c|c|}
\hline Tweet Focus & Current Awareness & Promotion & Miscellaneous \\
\hline Library & $\mathrm{n} / \mathrm{a}$ & $\begin{array}{l}\text { Treadwell Library @MGHTreadwell · Jun } 27 \\
\text { Treadwell Library July classes: Onsite, Online - } \\
\text { July 9, 10:30am } \\
\text { http://massgeneral.libcal.com/event.php?id=69512 } \\
\text { 3...... QUOSA - July 16, 10am } \\
\text { http://massgeneral.libcal.com/event.php?id=70048 } \\
6 . . .\end{array}$ & $\mathrm{n} / \mathrm{a}$ \\
\hline $\begin{array}{l}\text { Broader } \\
\text { Organization }\end{array}$ & $\begin{array}{l}\text { Retweeted by Frank Curtis } \\
\text { Library } \\
\text { NSFT mental health } \\
\text { @NSFTtweets · Jun } 27 \\
\text { Trust's first support workers } \\
\text { complete their training } \\
\text { \#suffolknhs \#norfolknhs } \\
\text { http://www.nsft.nhs.uk/Pages/Fir } \\
\text { st-Peer-Support-Workers- } \\
\text { complete-their-training.aspx ... }\end{array}$ & $\begin{array}{l}\text { Retweeted by Frank Curtis Library NCH\&C } \\
\text { @NCHC_NHS · Feb } 11 \\
\text { Smokefree Norfolk team are ready to help people } \\
\text { to give up smoking this \#nosmokingday } \\
\text { http://bit.ly/1aRDvpB @nhssmokefree } \\
\text { @NoSmokingDay }\end{array}$ & $\mathrm{n} / \mathrm{a}$ \\
\hline External & $\begin{array}{l}\text { Retweeted by Frank Curtis } \\
\text { Library The Mental Elf } \\
\text { @Mental_Elf · Feb } 14 \\
\text { Self-management: mapping the } \\
\text { strategies used by people with } \\
\text { depression } \\
\text { http://thementalelf.net/?p=8204 }\end{array}$ & $\begin{array}{l}\text { Retweeted by PublicHealth Library City of } \\
\text { Hamilton @cityofhamilton · Jun } 27 \\
\text { As Canada Day approaches, the \#HamOnt Fire } \\
\text { Department reminds everyone to stay safe when } \\
\text { handling fireworks. Tips - } \underline{\text { http:///bit.ly/1qiUc3K }}\end{array}$ & $\mathrm{n} / \mathrm{a}$ \\
\hline
\end{tabular}


Academic Libraries

\begin{tabular}{|c|c|c|c|}
\hline Tweet Focus & Current Awareness & Promotion & Miscellaneous \\
\hline Library & $\mathrm{n} / \mathrm{a}$ & $\begin{array}{l}\text { UCF COM Library @ucfcomhsl. } \\
\text { Feb } 12 \\
\text { ReelDX 60-day Trial now } \\
\text { available! http://wp.me/p2zcg6-ax }\end{array}$ & $\begin{array}{l}\text { TCMC Medical Library @tcmclibrary } \\
\text { · Jun } 23 \\
\text { Some librarian humor for your } \\
\text { Monday morning :) } \\
\text { http://fb.me/1y40GaOjk } \\
\end{array}$ \\
\hline $\begin{array}{l}\text { Broader } \\
\text { Organization }\end{array}$ & $\begin{array}{l}\text { Retweeted by UConn Health } \\
\text { Library } \\
\text { UConn Health @uconnhealth } \\
\text { · Aug } 12 \\
\text { Our X-country cycling med } \\
\text { students are back! See } \\
\text { @LouisaMoller's report on } \\
\text { \#CoastToCoastForACure } \\
\text { @FoxCT: } \\
\text { http://bit.ly/C2CFOX }\end{array}$ & $\begin{array}{l}\text { TCMC Medical Library } \\
\text { @tcmclibrary · Feb } 14 \\
\text { Need a last minute Valentine's Day } \\
\text { gift for your sweetie...or yourself? } \\
\text { Head down to the MBS Lobby } \\
\text { today from... } \\
\text { http://fb.me/1cNsmZIZ4 } \\
\end{array}$ & $\begin{array}{l}\text { NYMC Library @nymclibrary · Jun } \\
26 \\
\text { From the Archives... History of the } \\
\text { NYMC Alumni Center } \\
\text { http://wp.me/pVLs4-19E }\end{array}$ \\
\hline External & $\begin{array}{l}\text { VCU Tompkins-McCaw } \\
\text { @VCUTMLibrary · Feb } 10 \\
\text { Feeling powerless 'makes } \\
\text { tasks more physically } \\
\text { challenging' - Medical News } \\
\text { Today http://bit.ly/1coJHAk }\end{array}$ & $\begin{array}{l}\text { MCH Library @MCH_Library } \\
\text { Aug } 13 \\
\text { Need info on back-to-school } \\
\text { vaccinations? Contact a health } \\
\text { professional or your local or state } \\
\text { health department website. } \\
\text { \#NIAM14 }\end{array}$ & $\begin{array}{l}\text { TCMC Medical Library @tcmclibrary } \\
\text { · Apr } 25 \\
\text { I can't even stand the cuteness!! } \\
\text { Super Grover scales the building of } \\
\text { the Children's Hospital of } \\
\text { Philadelphia. <3 } \\
\text { http://fb.me/6SRaXAw4P } \\
\end{array}$ \\
\hline
\end{tabular}

